OPEN ACCESS

Edited by: Daniel Luke King, University of Adelaide, Australia

Reviewed by: Aviv M. Weinstein, Ariel University, Israel Domenico De Berardis, Azienda Usl Teramo, Italy

*Correspondence: Doug Hyun Han hduk@yahoo.com

Specialty section: This article was submitted to Addictive Disorders, a section of the journal Frontiers in Psychiatry

Received: 22 January 2018 Accepted: 27 March 2018 Published: 10 April 2018

Citation:

Bae S, Hong JS, Kim SM and Han DH (2018) Bupropion Shows Different Effects on Brain Functional

Connectivity in Patients With

Internet-Based Gambling Disorder and Internet Gaming Disorder.

Front. Psychiatry 9:130. doi: 10.3389/fpsyt.2018.00130

\section{Bupropion Shows Different Effects on Brain Functional Connectivity in Patients With Internet-Based Gambling Disorder and Internet Gaming Disorder}

\author{
Sujin Bae', Ji Sun Hong², Sun Mi Kim² and Doug Hyun Han²* \\ ${ }^{1}$ Industry Academic Cooperation Foundation, Chung-Ang University, Seoul, South Korea, ${ }^{2}$ Department of Psychiatry, \\ College of Medicine, Chung-Ang University, Seoul, South Korea
}

Introduction: Internet gaming disorder (IGD) and gambling disorder (GD) share similar clinical characteristics but show different brain functional connectivity patterns. Bupropion is known to be effective for the treatment of patients with IGD and GD. We hypothesized that bupropion may be effective for the treatment of Internet-based gambling disorder (ibGD) and IGD and that the connections between the default mode network (DMN) and cognitive control network (CCN) would be different between ibGD and IGD patients after 12 weeks of bupropion treatment.

Methods: 16 patients with IGD, 15 patients with ibGD, and 15 healthy subjects were recruited in this study. At baseline and after 12 weeks of bupropion treatment, the clinical symptoms of patients with IGD or ibGD were assessed, and brain activity was evaluated using resting state functional magnetic resonance imaging.

Results: After the 12-week bupropion treatment, clinical symptoms, including the severity of IGD or GD, depressive symptoms, attention, and impulsivity improved in both groups. In the IGD group, the functional connectivity (FC) within the posterior DMN as well as the FC between the DMN and the CCN decreased following treatment. Moreover, the FC within the DMN in the IGD group was positively correlated with changes in Young Internet Addiction Scale scores after the bupropion treatment period. In the ibGD group, the FC within the posterior DMN decreased while the FC within the CCN increased after the bupropion treatment period. Moreover, the FC within the CCN in the ibGD group was significantly greater than that in the IGD group.

Conclusion: Bupropion was effective in improving clinical symptoms in patients with IGD and ibGD. However, there were differences in the pharmacodynamics between the two groups. After 12 weeks of bupropion treatment, the FC within the DMN as well as between the DMN and CCN decreased in patients with IGD, whereas the FC within the CCN increased in patients with ibGD.

Keywords: Internet gaming disorder, gambling disorder, bupropion, default mode network, cognitive control network 


\section{INTRODUCTION}

Internet-based gambling is a modified form of gambling using Internet-enabled devices, including computers, mobile phones, and digital television $(1,2)$. Due to the characteristics of online systems such as speed and ease of accessibility, internet-based gambling may have a rapid feedback system and provide easy access to variable betting options $(1,2)$. Over the last two decades, Internet gaming disorder (IGD) has been regarded as a mental disease characterized by the urge for game (gambling) play, extensive playing time, and harmful side effects (3). Due to the similarities between IGD and internet-based gambling disorder (ibGD) with respect to the clinical symptoms of excessive use and the potential adverse effects, several studies have suggested that IGD may be diagnostically similar to ibGD (4). Because of these diagnostic similarities, medications for gambling disorder (GD), including escitalopram and bupropion, have also been applied to IGD (5-8). However, there has been controversy regarding the classification of IGD as an addiction or impulse control disorder $(3,9,10)$ as well as the differences in brain functional connectivity (FC) within the cognitive network between the two diseases (11). Therefore, a comparison of the effects of medication on the two diseases is warranted.

Among the several medications known to be effective for reducing the symptoms of GD $(5,6)$, bupropion has been suggested to improve the symptoms of IGD $(8,12)$. Bupropion is effective for treating patients with GD by decreasing gambling behavior and the amount of money spent $(5,6)$. Black et al. (5) reported that bupropion was effective and well tolerated in patients with GD (5). Dannon et al. (6) have suggested that bupropion is as effective as naltrexone based on its mechanism of regulating dopamine release. Bupropion acts to inhibit the reuptake of dopamine and norepinephrine by stimulating acetylcholine, hydroxytryptamine, gamma aminobutyric acid receptor, and endorphin signaling (13). These neurochemical systems may be associated with the urges, craving, and enjoyment accompanying gambling behaviors and addiction to drugs of abuse (14). The opioid antagonist naltrexone may block alcohol-induced dopamine release in the nucleus accumbens, which reduces the craving for alcohol and promotes abstinence (15). Studies have suggested that bupropion could improve the symptoms of IGD by improving comorbid depressive symptoms and inducing changes in brain activity $(8,16)$. Twelve weeks of bupropion treatment has been shown to improve IGD symptoms as well as depressive symptoms in patients with major depressive disorder and IGD (8). In another study, 6 weeks of bupropion treatment reduced the severity of IGD by decreasing brain activity within the dorsolateral prefrontal cortex in response to game stimulation (16).

In our previous study comparing the brain connectivity of the default mode network (DMN) and cognitive control network (CCN) between IGD and ibGD, both groups showed a similar decrease in FC in the DMN. However, FC within the CCN was increased in the IGD group but not the ibGD group (11). The $\mathrm{DMN}$ refers to functionally grouped areas that are synchronously deactivated during task performance and mainly activated during rest (17). The DMN was usually thought to consist of the posterior cingulate cortex (PCC), precuneus, medial frontal cortex
(mPFC), ventral anterior cingulate cortex (ACC), and lateral (LP) and inferior parietal lobes (IP) (17). In patients with substance dependence, the brain FC within the DMN was positively correlated with impulsivity (18). In patients with GD, decreased FC within the DMN from the PCC to the left superior frontal gyrus, right middle temporal gyrus, and precuneus was reported. In addition, the severity of GD was negatively correlated with the FC from the seed PCC to precuneus (19). However, previous studies on FC within the DMN in IGD have shown variable findings $(11,12)$. The FC within the posterior parts of the DMN in patients with IGD was decreased (11). By contrast, FC between the DMN and the salience network was increased in patients with IGD (12).

The CCN is correlated with the process of employing executive functions, including attention, planning, and working memory for guiding appropriate behaviors to achieve specific goals (20). It includes the dorsal regions of the lateral prefrontal cortex (DLPFC), ACC, and parietal cortex (20). As gambling and Internet gaming are associated with goal-directed decision-making (21), several scholars have suggested that the FC within the CCN would be associated with gambling and IGD (22). Moreover, the conflict and uncertainty resulting from risky decisionmaking during gambling tasks can activate the dorsal prefrontal cortex (23).

We hypothesized that bupropion might be effective for the treatment of ibGD and IGD. However, the mechanism of bupropion action in the treatment of ibGD and IGD in terms of brain connectivity between DMN and CCN would differ. We hypothesized that bupropion would decrease the FC between the DMN and CCN in the IGD group, but would increase the FC within the $\mathrm{CCN}$ in the ibGD group.

\section{MATERIALS AND METHODS}

\section{Participants}

Of the 15 patients with IGD and 14 patients with ibGD who participated in our previous study comparing brain connectivity (11), 12 patients with IGD and 12 patients with ibGD agreed to participate in this study. In addition, seven patients with IGD and six patients with ibGD who visited the outpatient department of OO hospital were newly recruited in this study (Figure 1). All participants were screened with the DSM-IV structural clinical interview for assessing psychiatric comorbidity (24). During the follow-up period, three patients with IGD and three patients with ibGD dropped out because of voluntary termination and changes in medication. Finally, 16 patients with IGD and 15 patients with ibGD completed the study protocol (Figure 1). The inclusion criteria were as follows: (1) diagnosed with IGD based on the DSM-5 or determined to have ibGD. We used the diagnostic criteria of GD and adapted it to form the inclusion criteria for ibGD, but changed "problematic gambling" in the DSM-5 to "ibGD," (2) adult (>18 years old), (3) male, and (4) psychiatric medication-naïve. The exclusion criteria were as follows: (1) other comorbid medical or psychiatric diseases, (2) low intelligence quotient (IQ) (less than 80), (3) contraindications for MRI scanning such as claustrophobia and metal implantation, and (4) history of substance abuse with the exception of social alcohol drinking and smoking. 


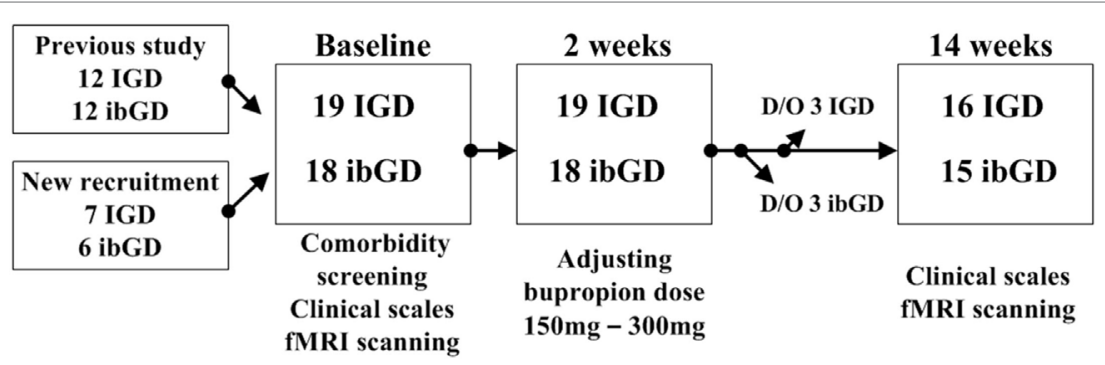

FIGURE 1 | Study procedure. Abbreviations: IGD, Internet gaming disorder; ibGD, Internet-based gambling disorder; D/O, dropped out; fMRI, functional magnetic resonance imaging.

\section{Procedure}

At baseline, all participants were asked to complete questionnaires for demographic data and clinical symptoms. The symptom severity of ibGD and IGD was assessed with the Yale-Brown Obsessive Compulsive Scale for pathologic gambling (YBOCS-PG) (25) and Young Internet Addiction Scale (YIAS) scores (26), respectively. Four more clinical symptom assessment scales were applied to all participants: the Beck Depression Inventory (BDI) (27) for depressive mood symptoms, the Korean ADHD Rating Scale (K-ARS) (28) for attention symptoms, and the Behavioral Inhibitory System and Behavioral Activation System scales for inhibitory and excitatory personal traits for aversive or appetitive motivations in behavior (29). The IQ of all participants was assessed using the Korean-Wechsler Adult Intelligence Scale (30). In addition, all participants were scanned to analyze brain FC via resting state functional magnetic resonance imaging (rs-fMRI). Both patients with IGD and ibGD were started on bupropion SR $150 \mathrm{mg} /$ day, which was then increased to $300 \mathrm{mg} /$ day. The decision to adjust the dose was made by a psychiatrist (Doug Hyun Han) at the second-week visit on the basis of tolerability and efficacy. At the end of 12 weeks of bupropion treatment, clinical scales and rs-fMRI scans were repeated in all participants (Figure 1). The Chung-Ang University Hospital Institutional Review Board approved the research protocol for this study, and written informed consent was provided by all participants.

\section{MRI Acquisition and Preprocessing}

Brain FC in the resting state was assessed using $3 \mathrm{~T}$ blood-oxygenlevel dependent functional MRI (Philips Achieva 3.0 T TX MRI scanner; TR = $3 \mathrm{~s}$; scan period, $12 \mathrm{~min} ; 240$ volumes; $128 \times 128$ matrix; 40 slices at a 4.0 -mm slice thickness). Preprocessing consisted of despiking (AFNI: 3dDespike), motion correction (SPM 12b), coregistration to Magnetization Prepared RApid Gradient Echo image (SPM 12b), normalization to MNI space (SPM $12 \mathrm{~b})$, temporal detrend (Matlab: detrend.m), bandpass filtering (Matlab: idealfilter.m), and voxelwise regression of identically bandpass filtered time series of six head motion parameters (realignment steps with six rigid-body parameters characterizing the estimated subject motion for each subject), degraded cerebrospinal fluid, degraded white matter, and facial soft tissues (Matlab) as previously described (31). To address the possibility of microhead movements affecting connectivity results (32), censoring of time points with a head motion $>0.2 \mathrm{~mm}$ was performed, but no regression of the global signal was performed (31).

We extracted 12 regions of two brain networks [four from the DMN: mPFC, right/left lateral parietal cortex (LPRt/LPLt), and PCC; eight from the CCN: right/left DLPFC (DLPFCRt/DLPFCLt), right/left inferior PFC (IFGRt/IFGLt), right/left posterior parietal cortex (PPCRt/PPCLt), and right/left presupplementary motor area] from the AAL atlas of the brain (networks.nii/.txt/.info). Using the CONN-fMRI functional connectivity toolbox (ver.15; www.Nitrc.org/projects/conn), Fisher-transformed correlation coefficients were calculated for each pair of regions of interest in each subject. Between-group effects were considered significant with a cluster-level false discovery rate $(F D R) q<0.05$, considering the multiple comparison correction over the correction of 66 pairs of 12 regions.

\section{Statistics}

Demographic and clinical characteristics of IGD, ibGD, and healthy comparison subjects were analyzed using analysis of variance (ANOVA) tests with statistical significance set at $p<0.05$. The correlations between clinical scales and brain connectivity were assessed using Spearman correlation with statistical significance set at $p<0.05$. All statistical assessments were performed using SPSS 18.0 (SPSS Inc., Chicago, IL, USA).

\section{RESULTS}

\section{Changes in Clinical Symptoms After 12 Weeks of Bupropion Treatment}

At baseline, there were no significant differences in age, education years, and IQ between IGD patients, ibGD patients, and healthy comparison subjects. However, there were significant differences in BISBAS $(F=6.56, p<0.01)$, BDI $(F=4.68, p=0.02)$, K-ARS $(F=24.09, p<0.01)$, YIAS $(F=70.94, p<0.01)$, and YBOCS-PG $(F=82.68, p<0.01)$ scores between the three groups. The post hoc test showed no significant differences in BDI, K-ARS, and BISBAS scores between the IGD and ibGD groups. The YIAS scores in the IGD group were higher than those in the ibGD group $(z=4.58$, $p<0.01)$ while the YBOCS-PG scores in the ibGD group were higher than those in the IGD group $(z=4.60, p<0.01)$ (Table 1).

After the 12-week bupropion treatment, the BDI $(z=-2.68$, $p<0.01)$, K-ARS $(z=-2.81, p<0.01)$, BISBAS $(z=-2.81$, 
TABLE 1 | Demographic and clinical characteristics.

\begin{tabular}{|c|c|c|c|c|c|}
\hline & \multicolumn{2}{|c|}{ IGD } & \multicolumn{2}{|c|}{ ibGD } & \multirow[t]{2}{*}{$\mathrm{HC}$} \\
\hline & Baseline & Follow-up & Baseline & Follow-up & \\
\hline Age & \multicolumn{2}{|c|}{$25.3 \pm 5.2$} & \multicolumn{2}{|c|}{$25.0 \pm 4.9$} & $25.7 \pm 4.7$ \\
\hline $\begin{array}{l}\text { Education } \\
\text { year }\end{array}$ & \multicolumn{2}{|c|}{$12.8 \pm 2.6$} & \multicolumn{2}{|c|}{$12.1 \pm 2.5$} & $13.1 \pm 2.3$ \\
\hline $\mathrm{IQ}$ & \multicolumn{2}{|c|}{$99.0 \pm 12.5$} & \multicolumn{2}{|c|}{$97.7 \pm 15.3$} & $103.8 \pm 9.9$ \\
\hline $\begin{array}{l}\text { Alcohol } \\
\text { (yes/no) }\end{array}$ & \multicolumn{2}{|c|}{$10 / 6$} & \multicolumn{2}{|c|}{$10 / 5$} & $12 / 3$ \\
\hline $\begin{array}{l}\text { Smoking } \\
\text { (yes/no) }\end{array}$ & \multicolumn{2}{|c|}{$8 / 8$} & \multicolumn{2}{|c|}{$9 / 6$} & $8 / 7$ \\
\hline $\mathrm{BDI}$ & $9.7 \pm 56.2$ & $5.7 \pm 2.8$ & $14.1 \pm 8.3$ & $9.4 \pm 3.4$ & $6.1 \pm 4.2$ \\
\hline $\mathrm{K}-\mathrm{ARS}$ & $13.0 \pm 4.5$ & $9.3 \pm 3.1$ & $18.8 \pm 7.7$ & $14.4 \pm 4.9$ & $5.4 \pm 3.4$ \\
\hline BISBAS & $47.6 \pm 4.9$ & $47.6 \pm 4.9$ & $50.7 \pm 6.0$ & $50.7 \pm 6.0$ & $49.0 \pm 8.1$ \\
\hline YIAS & $68.9 \pm 8.8$ & $54.8 \pm 8.2$ & $38.3 \pm 9.0$ & $36.5 \pm 7.4$ & $37.6 \pm 6.6$ \\
\hline $\begin{array}{l}\text { YBOCS- } \\
\text { PG }\end{array}$ & $5.7 \pm 2.2$ & $5.1 \pm 1.8$ & $17.8 \pm 4.6$ & $12.2 \pm 4.3$ & $4.1 \pm 1.8$ \\
\hline
\end{tabular}

IGD, Internet gaming disorder; ibGD, Internet-based gaming disorder; HC, healthy comparison subjects; IQ, intelligence quotient; BDI, Beck Depression Inventory; K-ARS, Korean ADHD Rating Scale; BISBAS, Behavioral Inhibitory System Behavioral Activation System; YIAS, Young Internet Addiction Scale; YBOCS-PG, Yale-Brown Obsessive Compulsive Scale for pathologic gambling.

$p<0.01)$, and YIAS $(z=-2.81, p<0.01)$ scores improved in the IGD group while the BDI $(z=-2.09, p=0.04)$, K-ARS $(z=-2.81, p<0.01)$, BISBAS $(z=-2.81, p<0.01)$, and YBOCS-PG $(z=-2.80, p<0.01)$ scores improved in the ibGD group. However, there were no significant intergroup differences with regards to changes in the clinical scales during the 12 -week period (Table 1).

\section{Changes in Brain FC After 12 Weeks of Bupropion Treatment}

In the IGD group at baseline, the FC between the MPFC and IFGLt $(t=3.39$, FDRq $=0.0026)$, DLPFCLt and LPRt $(t=3.34$, FDRq $=0.0030)$, and PPCLt and IFGRt $(t=3.67$, $\mathrm{FDRq}=0.0013$ ) was higher than that in the healthy subjects. After 12 weeks of bupropion treatment, the FC between the PCC and LPRt $(t=-3.26, \mathrm{FDRq}=0.0017)$, LPRt and PPCRt $(t=-3.16, \mathrm{FDRq}=0.0023)$, and LPRt and PPCLt $(t=-3.42$, FDRq $=0.0012$ ) were lower than baseline (Figure 2).

In the ibGD group at baseline, the FC between the PCC and LPLt $(t=-3.36$, FDRq $=0.0014)$ as well as PCC and LPRt $(t=-3.26, \mathrm{FDRq}=0.0027)$ was lower than that in healthy subjects. After 12 weeks of bupropion treatment, the FC between the PCC and PPCLt $(t=-3.23, \mathrm{FDRq}=0.0031)$ as well as the PCC and PPCRt $(t=-3.25, \mathrm{FDRq}=0.0031)$ was decreased while that between PPCLt and PPCRt $(t=3.12, \mathrm{FDRq}=0.0042)$ had increased compared with baseline (Figure 2).

A repeated measures ANOVA revealed that the ibGD group showed increased FC between IFGRt and PPCLt $(F=3.67$, $p=0.0013$ ), compared with the IGD group (Figure 2).

\section{Correlation Between the Changes in Clinical Scales and the Changes in Brain FC}

In the IGD group, the functional correlation between PCC and LPRt was positively correlated with changes in YIAS scores from

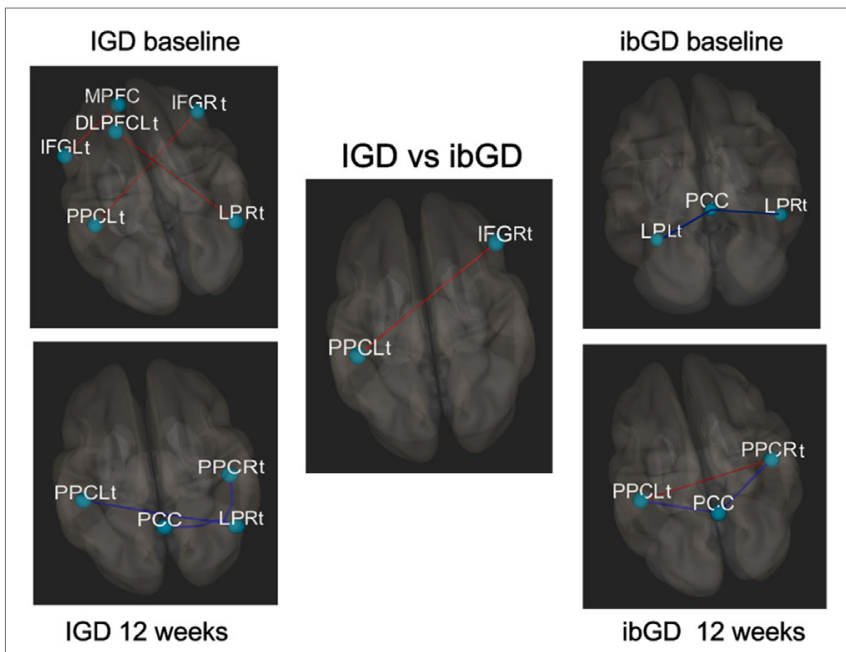

FIGURE 2 | Changes in brain functional connectivity after 12 weeks of bupropion treatment. Red line: increased functional connectivity (FC), blue line: decreased FC, In the IGD group at baseline, the functional correlation between the middle frontal gyrus (MPFC) and left inferior prefrontal cortex (IFGLt) $(t=3.39, \mathrm{FDRq}=0.0026)$, left dorsolateral prefrontal cortex (DLPFCLt) and right lateral parietal cortex (LPRt) $(t=3.34, \mathrm{FDRq}=0.0030$ ), and left posterior parietal cortex (PPCLt) and IFGRt $(t=3.67$,

$F D R q=0.0013)$. At 12 weeks, the functional correlation between the posterior cingulate cortex (PCC) and LPRt $(t=-3.26, \mathrm{FDRq}=0.0017)$, LPRt and PPCRt ( $t=-3.16, \mathrm{FDRq}=0.0023)$, and LPRt and PPCLt $(t=-3.42$, $F D R q=0.0012)$. In ibGD group at baseline, the functional correlation between the PCC and LPLt $(t=-3.36, \mathrm{FDRq}=0.0014), \mathrm{PCC}$ and LPRt $(t=-3.26, \mathrm{FDRq}=0.0027)$. At 12 weeks, the functional correlation between the PCC and PPCLt $(t=-3.23, \mathrm{FDRq}=0.0031)$, PCC and PPCRt $(t=-3.25, \mathrm{FDRq}=0.0031)$. The functional correlation between the PPCLt and PPCRt ( $t=3.12, \mathrm{FDRq}=0.0042)$. In the IGD vs ibGD comparison (repeated measure analysis of variance), the ibGD group showed increased FC between IFGRt and PPCLt ( $F=3.67, p=0.0013)$, compared with IGD group.

baseline to 12 weeks ( $r=0.69, p<0.01$ ). In the ibGD group, the changes in FC between the PPCLt and PPCRt were negatively correlated with the changes in YBOCS-PG scores from baseline to 12 weeks $(r=-0.68, p<0.01$ ) (Figure 3).

\section{DISCUSSION}

\section{Changes in Clinical Symptoms in Response to Bupropion Treatment}

In this study, 12-week bupropion treatment improved the severity of IGD and ibGD as well as the associated clinical symptoms in both patient groups. The effectiveness of bupropion for the treatment for IGD has been reported in previous studies $(8,16)$. Twelve weeks of bupropion treatment has been shown to reduce the severity of IGD as well as depressive symptoms in IGD patients with major depressive disorder (8). In a comparison of escitalopram and bupropion treatment, bupropion showed greater effectiveness in improving impulsivity and attention (12). The effectiveness of bupropion in patients with GD is a matter of debate $(5,6)$. Although Black et al. (5) reported the effectiveness and tolerability of bupropion in patients with GD, its effectiveness 

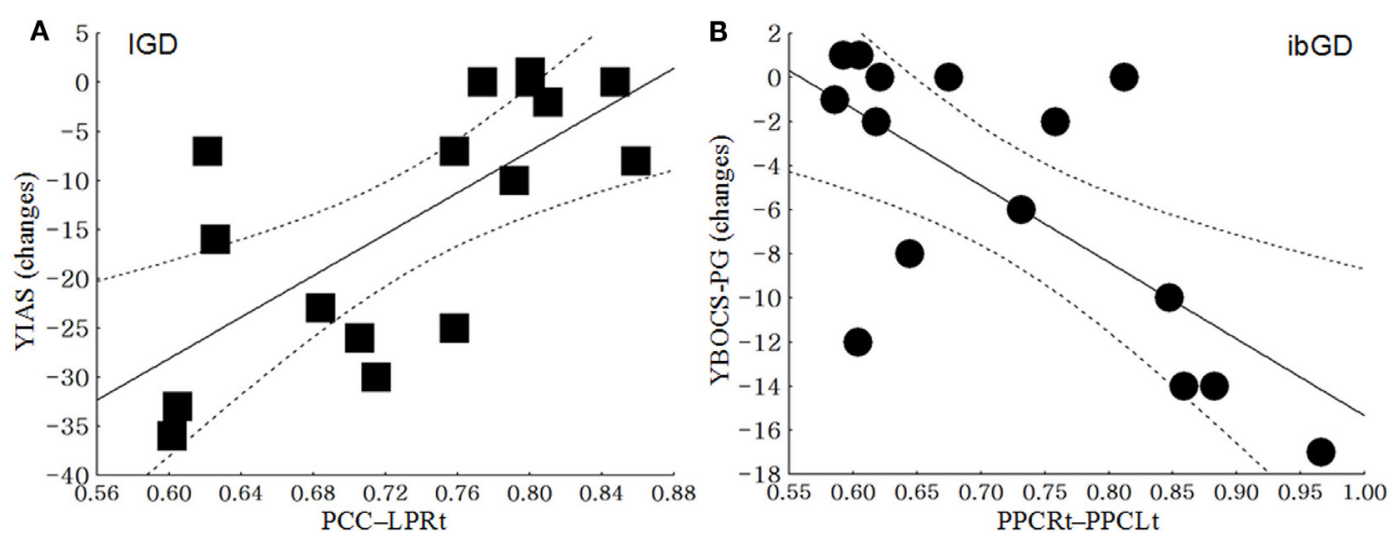

FIGURE 3 | Correlation between the changes in clinical scales and the changes in brain functional connectivity. (A) In the Internet gaming disorder (IGD) group, the functional connectivity between the posterior cingulate cortex (PCC) and right lateral parietal cortex (LPRt) was positively correlated with the changes in the Young Internet Addiction Scale scores from baseline to 12 weeks $(r=0.69, p<0.01)$. (B) In the ibGD group, the changes in FC between the left posterior parietal cortex (PPCLt) and right posterior parietal cortex (PPCRt) were negatively correlated with the changes in the Yale-Brown Obsessive Compulsive Scale for pathologic gambling (YBOCS-PG) scores from baseline to 12 weeks $(r=-0.68, p<0.01)$.

in GD symptom reduction was not greater than that of placebo (5). However, Dannon et al. (6) declared that bupropion was as effective as naltrexone in patients with GD (6). Due to the dual action of bupropion with regards to the inhibition of norepinephrine and dopamine reuptake, it is thought to be effective for reducing impulsive behaviors in both IGD and ibGD patients $(33,34)$. Impulsivity is a well-known correlate of prototypical behavioral addictions with steep discounting of delayed rewards (35). This steep discounting of delayed rewards is associated with the dopamine-based neuromodulatory system (36).

\section{Changes in Brain FC After 12 Weeks of Bupropion Treatment}

In response to 12 weeks of bupropion treatment, the FC within the DMN as well as that between the DMN and CCN decreased in the IGD group, while the FC within the CCN increased in the ibGD group. The IGD and ibGD groups showed different brain FC patterns in response to bupropion treatment. In the IGD group, the FC within the posterior DMN as well as the FC between the $\mathrm{DMN}$ and $\mathrm{CCN}$ decreased after the 12-week treatment period. Moreover, the FC between the PCC and LPRt in the IGD group was positively correlated with changes in YIAS after the 12-week bupropion treatment period. These results were consistent with our previous study showing decreased FC within the DMN and between the DMN and the salience network (12). Decreased FC within the DMN may be associated with increased norepinephrine and dopamine, as observed in the $\mathrm{DMN}$ in response to the administration of atomoxetine (37). The dual action of bupropion in increasing norepinephrine and dopamine signaling is similar to the mechanism of action of modafinil (38). The increased FC within the DMN was thought to be related to impulsivity, risky decision-making, and attention deficits $(17,39)$. Therefore, decreasing the FC within the DMN and the FC between the $\mathrm{DMN}$ and other networks may reduce impulsive behavior, such as excessive Internet game-playing or gambling.

In the ibGD group, the FC within the posterior DMN decreased while that within the $\mathrm{CCN}$ increased after the 12-week bupropion treatment period. Moreover, the FC within the CCN (IFGRt PPCLt) in the ibGD group was much higher than that in the IGD group. The FC within the CCN (PPCLt - PPCRt) in the IGD group was negatively correlated with changes in the YBOCS-PG scores after the 12-week bupropion treatment period. The failure of self-regulation in patients with GD is thought to occur due to failure in prefrontal-mediated top-down inhibitory control (40). The top-down circuitry is reported to be associated with decision errors (36) as well as dopamine transmission (41). In addition, areas of the fronto-parietal cortices are engaged in top-down attention and cognitive control (42). Therefore, the pharmacodynamic activity of bupropion (dopamine stimulation) may enhance the CCN (fronto-parietal areas) by promoting activity within the top-down circuitry in patients with ibGD. Taken together, IGD and ibGD appear to share similar characteristics of decreased impulsivity and decreased FC within the DMN after bupropion treatment. However, bupropion was more effective at increasing the FC within the $\mathrm{CCN}$, which is associated with the correction of decision errors.

\section{Limitations}

There were several limitations in this study. First, the small number of subjects limits the generalizability of the results. Due to the small number of subjects, only two brain networks of interest were used to compare the FC changes between the two groups in response to bupropion treatment. Second, as this study did not have a placebo control group, we cannot rule out the possibility that we were seeing a placebo effect. Finally, because the healthy control subjects did not participate in follow-up assessments, we did not have a measure of test-retest variability. Future studies should include a larger number of subjects as well as follow-up information for healthy control subjects.

\section{CONCLUSION}

Bupropion shows promise for improving problematic behaviors in both IGD and ibGD. However, the pharmacodynamics 
of bupropion differed between the two groups, whereby the FC within the DMN as well as between the DMN and CCN decreased in patients with IGD, whereas the FC within the CCN increased in patients with ibGD after 12 weeks of bupropion treatment.

\section{ETHICS STATEMENT}

The Chung-Ang University Hospital Institutional Review Board approved the research protocol for this study, and written informed consent was provided by all participants.

\section{REFERENCES}

1. Gainsbury SM, Russell A, Hing N, Wood R, Lubman D, Blaszczynski A. How the Internet is changing gambling: findings from an Australian Prevalence Survey. J Gambl Stud (2015) 31(1):1-15. doi:10.1007/s10899-013-9404-7

2. Monaghan S. Responsible gambling strategies for Internet gambling: the theoretical and empirical base of using pop-up messages to encourage selfawareness. Comput Hum Behav (2009) 25:202-7. doi:10.1016/j.chb.2008.08.008

3. Carbonell X, Guardiola E, Fuster H, Gil F, Panova T. Trends in scientific literature on addiction to the Internet, video games, and cell phones from 2006 to 2010. Int J Prev Med (2016) 7:63. doi:10.4103/2008-7802.179511

4. Dowling NA. Issues raised by the DSM-5 Internet gaming disorder classification and proposed diagnostic criteria. Addiction (2014) 109(9):1408-9. doi:10.1111/add.12554

5. Black DW, Arndt S, Coryell WH, Argo T, Forbush KT, Shaw MC, et al. Bupropion in the treatment of pathological gambling: a randomized, doubleblind, placebo-controlled, flexible-dose study. J Clin Psychopharmacol (2007) 27(2):143-50. doi:10.1097/01.jcp.0000264985.25109.25

6. Dannon PN, Lowengrub K, Musin E, Gonopolski Y, Kotler M. Sustainedrelease bupropion versus naltrexone in the treatment of pathological gambling: a preliminary blind-rater study. J Clin Psychopharmacol (2005) 25(6):593-6. doi:10.1097/01.jcp.0000186867.90289.ed

7. Dell'Osso B, Hadley S, Allen A, Baker B, Chaplin WF, Hollander E. Escitalopram in the treatment of impulsive-compulsive Internet usage disorder: an open-label trial followed by a double-blind discontinuation phase. J Clin Psychiatry (2008) 69(3):452-6. doi:10.4088/JCP.v69n0316

8. Han DH, Renshaw PF. Bupropion in the treatment of problematic online game play in patients with major depressive disorder. J Psychopharmacol (2012) 26(5):689-96. doi:10.1177/0269881111400647

9. APA. Diagnostic and Statistical Manual of Mental Disorders. Arlington, VA: American Psychiatric Publishing (2013).

10. Shapira NA, Goldsmith TD, Keck PE Jr, Khosla UM, McElroy SL. Psychiatric features of individuals with problematic Internet use. J Affect Disord (2000) 57(1-3):267-72. doi:10.1016/S0165-0327(99)00107-X

11. Bae S, Han DH, Jung J, Nam KC, Renshaw PF. Comparison of brain connectivity between Internet gambling disorder and Internet gaming disorder: a preliminary study. J Behav Addict (2017) 6(4):505-15. doi:10.1556/2006.6. 2017.061

12. Nam B, Bae S, Kim SM, Hong JS, Han DH. Comparing the effects of bupropion and escitalopram on excessive Internet game play in patients with major depressive disorder. Clin Psychopharmacol Neurosci (2017) 15(4):361-8. doi:10.9758/cpn.2017.15.4.361

13. Gelenberg A, Bassuk EL. The Practitioner's Guide to Psychoactive Drugs. 4th ed. New York: Plenum Medical Book Co (1997).

14. Bechara A. Risky business: emotion, decision-making, and addiction. J Gambl Stud (2013) 19(1):23-51. doi:10.1023/A:1021223113233

15. Volpicelli JR. Alcohol abuse and alcoholism: an overview. J Clin Psychiatry (2001) 62(20):4-10.

16. Han DH, Hwang JW, Renshaw PF. Bupropion sustained release treatment decreases craving for video games and cue-induced brain activity in patients with Internet video game addiction. Exp Clin Psychopharmacol (2010) 18(4):297-304. doi:10.1037/a0020023

\section{AUTHOR CONTRIBUTIONS}

$\mathrm{JH}, \mathrm{SK}$, and DH contributed to patients' recruitment, data collection, and processing. $\mathrm{SB}, \mathrm{JH}$, and $\mathrm{DH}$ analyzed the data. All the authors participated to drawing up the manuscript, were involved to the intellectual workup for the article, and read and approved the final manuscript.

\section{FUNDING}

This study was supported by a grant from the Korean Creative Content Agency (R2014040055).

17. Raichle ME, MacLeod AM, Snyder AZ, Powers WJ, Gusnard DA, Shulman GL. A default mode of brain function. Proc Natl Acad Sci U S A (2001) 98(2):676-82. doi:10.1073/pnas.98.2.676

18. Regner MF, Saenz N, Maharajh K, Yamamoto DJ, Mohl B, Wylie K, et al. Top-down network effective connectivity in abstinent substance dependent individuals. PLoS One (2016) 11(10):e0164818. doi:10.1371/journal.pone. 0164818

19. Jung MH, Kim JH, Shin YC, Jung WH, Jang JH, Choi JS, et al. Decreased connectivity of the default mode network in pathological gambling: a resting state functional MRI study. Neurosci Lett (2014) 583:120-5. doi:10.1016/j. neulet.2014.09.025

20. Breukelaar IA, Antees C, Grieve SM, Foster SL, Gomes L, Williams LM, et al. Cognitive control network anatomy correlates with neurocognitive behavior: a longitudinal study. Hum Brain Mapp (2017) 38(2):631-43. doi:10.1002/ hbm. 23401

21. Cole MW, Schneider W. The cognitive control network: integrated cortical regions with dissociable functions. Neuroimage (2007) 37(1):343-60. doi:10.1016/j.neuroimage.2007.03.071

22. Sohrabi A, Smith AM, West RL, Cameron I. An fMRI study of risky decision making: the role of mental preparation and conflict. Basic Clin Neurosci (2015) 6(4):265-70.

23. Li TM, Chau M, Wong PW, Lai ES, Yip PS. Evaluation of a Web-based social network electronic game in enhancing mental health literacy for young people. J Med Internet Res (2013) 15(5):e80. doi:10.2196/jmir.2316

24. First MB, Spitzer RL, Gibbon M, Williams J. Structured Clinical Interview for DSM-IV Axis I Disorder. New York, NY: New York State Psychiatric Institute (1996).

25. Pallanti S, DeCaria CM, Grant JE, Urpe M, Hollander E. Reliability and validity of the pathological gambling adaptation of the Yale-Brown ObsessiveCompulsive Scale (PG-YBOCS). J Gambl Stud (2005) 21(4):431-43. doi:10.1007/s10899-005-5557-3

26. Young KS. Psychology of computer use: XL. Addictive use of the Internet: a case that breaks the stereotype. Psychol Rep (1996) 79:899-902. doi:10.2466/ pr0.1996.79.3.899

27. Beck AT, Ward CH, Mendelson M, Mock J, Erbaugh J. An inventory for measuring depression. Arch Gen Psychiatry (1961) 4:561-71. doi:10.1001/ archpsyc.1961.01710120031004

28. So YK, Noh JS, Kim YS, Ko SG, Koh YJ. The reliability and validity of Korean Parent and Teacher ADHD Rating Scale. J Kor Nueropsych Assoc (2002) 41:283-9. doi:10.1177/1087054712461177

29. Kim KH, Kim WS. Korean-BAS/BIS scale. Kor J Health Psychol (2001) 6(2):19-37.

30. Kim JK, Yum TH, Oh KJ, Park YS, Lee YH. Factor analysis of K-WAIS revised version. Kor J Clin Psychol (1992) 11:1-10.

31. Anderson JS, Druzgal TJ, Lopez-Larson M, Jeong EK, Desai K, YurgelunTodd D. Network anticorrelations, global regression, and phase-shifted soft tissue correction. Hum Brain Mapp (2011) 32(6):919-34. doi:10.1002/hbm. 21079

32. Power JD, Barnes KA, Snyder AZ, Schlaggar BL, Petersen SE. Spurious but systematic correlations in functional connectivity MRI networks arise from subject motion. Neuroimage (2012) 59(3):2142-54. doi:10.1016/j. neuroimage.2011.10.018 
33. Ascher JA, Cole JO, Colin JN, Feighner JP, Ferris RM, Fibiger HC, et al. Bupropion: a review of its mechanism of antidepressant activity [research support, non-U.S. Gov't review]. J Clin Psychiatry (1995) 56(9):395-401.

34. Cooper BR, Wang CM, Cox RF, Norton R, Shea V, Ferris RM. Evidence that the acute behavioral and electrophysiological effects of bupropion (Wellbutrin) are mediated by a noradrenergic mechanism. Neuropsychopharmacology (1994) 11(2):133-41. doi:10.1038/npp.1994.43

35. Nakagawa H, Whelan K, Lynch JP. Mechanisms of Barrett's oesophagus: intestinal differentiation, stem cells, and tissue models [research support, N.I.H., extramural review]. Best Pract Res Clin Gastroenterol (2015) 29(1):3-16. doi:10.1016/j.bpg.2014.11.001

36. Volkow ND, Baler RD. NOW vs LATER brain circuits: implications for obesity and addiction [review]. Trends Neurosci (2015) 38(6):345-52. doi:10.1016/j. tins.2015.04.002

37. Bymaster FP, Katner JS, Nelson DL, Hemrick-Luecke SK, Threlkeld PG, Heiligenstein JH, et al. Atomoxetine increases extracellular levels of norepinephrine and dopamine in prefrontal cortex of rat: a potential mechanism for efficacy in attention deficit/hyperactivity disorder. Neuropsychopharmacology (2002) 27:699-711. doi:10.1016/S0893-133X(02)00346-9

38. Lin HY, Gau SS. Atomoxetine treatment strengthens an anti-correlated relationship between functional brain networks in medication-naive adults with attention-deficit hyperactivity disorder: a randomized double-blind placebo-controlled clinical trial. Int J Neuropsychopharmacol (2015) 19:yv094. doi:10.1093/ijnp/pyv094
39. Han DH, Kim SM, Bae S, Renshaw PF, Anderson JS. A failure of suppression within the default mode network in depressed adolescents with compulsive Internet game play. JAffect Disord (2016) 194:57-64. doi:10.1016/j. jad.2016.01.013

40. Everitt BJ, Robbins TW. Drug addiction: updating actions to habits to compulsions ten years on [research support, Non-U.S. Gov't review]. Annu Rev Psychol (2016) 67:23-50. doi:10.1146/annurev-psych-122414-033457

41. Voon V, Fernagut PO, Wickens J, Baunez C, Rodriguez M, Pavon N, et al. Chronic dopaminergic stimulation in Parkinson's disease: from dyskinesias to impulse control disorders [review]. Lancet Neurol (2009) 8(12):1140-9. doi:10.1016/S1474-4422(09)70287-X

42. Brown TI, Uncapher MR, Chow TE, Eberhardt JL, Wagner AD. Cognitive control, attention, and the other race effect in memory [clinical trial]. PLoS One (2017) 12(3):e0173579. doi:10.1371/journal.pone.0173579

Conflict of Interest Statement: No competing personal, professional, or financial interests exist.

Copyright $\odot 2018$ Bae, Hong, Kim and Han. This is an open-access article distributed under the terms of the Creative Commons Attribution License (CC BY). The use, distribution or reproduction in other forums is permitted, provided the original author(s) and the copyright owner are credited and that the original publication in this journal is cited, in accordance with accepted academic practice. No use, distribution or reproduction is permitted which does not comply with these terms. 